\title{
The Effects of Vagotomy on the Abomasum in Calves: Radiography and Protein Gene Product 9.5 Immunohistochemistry
}

\author{
Raden Harry SOEHARTONO ${ }^{1)}$, Haruo YAMADA ${ }^{1)}$, Norio YAMAGISHI ${ }^{1}$, Nobuo KITAMURA $^{2)}$ and \\ Kiyoshi TAGUCHI ${ }^{3)}$ \\ ${ }^{1)}$ Department of Veterinary Surgery and ${ }^{2)}$ Veterinary Anatomy, School of Veterinary Medicine, Obihiro University of Agriculture and \\ Veterinary Medicine, Obihiro 080-8555, and ${ }^{3}$ Department of Veterinary Surgery II, Faculty of Veterinary Medicine, Rakuno Gakuen \\ University, Ebetsu 069-8501, Japan
}

(Received 3 October 2000/Accepted 15 February 2001)

ABSTRACT. Abomasal disorders of calves with total vagotomy, operated on at 1 week old, were investigated with radiography and protein gene product (PGP) 9.5 immunohistochemistry. Radiographic findings indicated abomasal atony with dilatation in all calves 2 weeks after vagotomy, while 4 weeks after vagotomy abomasal dilatation was detected in 2 calves and another 2 calves showed dilatation and impaction. The densities of PGP 9.5-immunoreactive nerves in the tunica muscularis decreased significantly in the corpus region of the greater curvature 2 weeks after vagotomy and in the pyloric region of the lesser curvature 4 weeks after vagotomy, and it was at its lowest 4 weeks after vagotomy in all regions examined. In conclusion, abomasal dilatation and/or impaction in vagotomized calves confirmed by radiography were related with a decreased frequency of nerves in the tunica muscularis of the abomasum. KEY WORDS: abomasal disorder, PGP 9.5, vagotomy.

J. Vet. Med. Sci. 63(6): 671-674, 2001

Gastric motility is greatly influenced by the vagus nerves whose activity is integrated by gastric centers in the medulla oblongata $[6,18]$. This innervation is of much greater importance in ruminants than in other species [11]. Since the abomasum retains considerable activity after vagotomy, the importance of its innervation contrasts markedly with that of the forestomach [5]. In the milk-fed calf, the abomasum has a more important role in digestion than the still undeveloped forestomach. The vagus may control abomasal motility through its innervation of the tunica muscularis. Mechanical malfunction of the abomasum in cattle might involve the disorder of vagal innervation through the dorsal and ventral vagal nerves which ramify to the abomasum [2]. Although a vagal nervous dysfunction has been suggested as a possible cause of abomasal disorders [16], vagal nerve injury in the abomasal wall is still uncertain. The distribution of vagal nerve endings in the sheep stomach has been reported after short-term vagotomy [15], however, the long-term effects of vagotomy on the mural innervation of the ruminant stomach have not been described.

Radiographic studies of the abomasum of lambs and calves before and after vagotomy were mostly undertaken during motility [17] and abomasal emptying [1]. The former was a short-term investigation while the latter maintained the calf after vagotomy by cannulation feeding into the abomasum. The radiography of the long-term effects of vagotomy on the abomasum maintained with normal feeding has not yet been reported. Furthermore, radiographic findings on the functional state of the abomasum have not yet been compared with the histology of the regulatory systems in the abomasal wall.

Protein gene product 9.5 (PGP) is a neuronal soluble protein distributed in the central and peripheral nervous sys- tems of different animals [14, 20]. It is useful as a general immunohistochemical marker for nervous elements and for the assessment of neuronal development and the detection of neuronal damage in diseases of the nervous system of various animals including cattle and sheep [4, 12, 19, 22].

The present study investigated the general distribution and frequency of nervous elements as revealed by PGP 9.5 immunohistochemistry in the tunica muscularis of the abomasum, referring to the radiographic findings on abomasal disorders caused by the long-term effects of vagotomy on nursing calves compared with those of normal calves.

A total of 17 dairy calves were divided into 2 groups: non-vagotomized control ( 3 calves each at 1, 3 and 5 weeks of age), and vagotomized ( 4 calves each at 3 and 5 weeks of age, 2 and 4 weeks after vagotomy, respectively). The animals were bottle-fed with $2 l$ milk $(10 \% \mathrm{w} / \mathrm{v}$ commercial milk replacement food) twice a day from 1 week old. Roughage was withheld.

Under general anesthesia, a total thoraco-vagotomy was undertaken at 1 week old through a left side thoracic incision at the level of the 7 th rib. Both sides of the dorsal and ventral vagi were cut $3 \mathrm{~cm}$ in length at the level of the 7 th rib.

Radiographs were taken using an X-ray machine (DRP104, Hitachi Medico Co., Ltd., Tokyo, Japan) at 70 kV, 30 $\mathrm{mA}, 0.08 \mathrm{sec}$ setting with $90 \mathrm{~cm}$ focus film. Barium sulfate powder was added to $2 l$ milk in proportions of $10 \%(\mathrm{w} / \mathrm{v})$. Radiographs of the left lateral abdomen were made just before and once a week after vagotomy. Weekly radiographs were taken of control animals.

The animals were euthanatized under pentobarbital anesthesia and exsanguinated. The abomasum was immediately dissected out and tissue samples were collected from 8 regions: cardiac, corpus, proximal and distal pyloric regions 

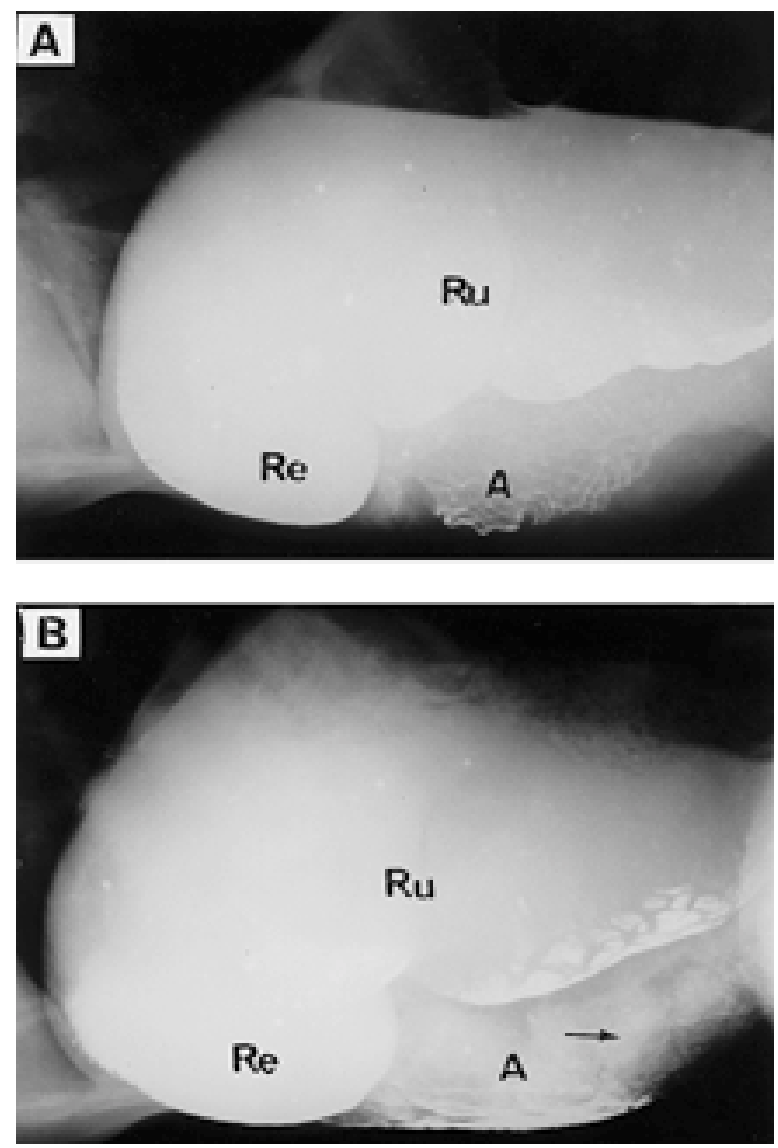

Fig. 1. Radiographs made after sucking milk containing BaSO4. A) Two weeks after vagotomy. Radiopaque material was presented in the rumen $(\mathrm{Ru})$, reticulum $(\mathrm{Re})$ and abomasum $(\mathrm{A})$. Abomasal atony with dilatation can be seen. B) Four weeks after vagotomy. The abomasum impaction [arrow] is noted by accumulation with clotted milk.

of the lesser and greater curvatures of the abomasum. The distal pyloric region of the lesser curvature is the area of the torus pyloricus. The samples were fixed in phosphate buffer ( $\mathrm{pH}$ 7.4) containing $10 \%$ formalin for more than 1 week, and processed routinely for embedding in paraffin. Sections were cut $10 \mu \mathrm{m}$ in thickness and mounted on poly-L-lysin coated slides. After deparaffinization, sections were processed for PGP 9.5 immunohistochemistry by the avidinbiotin-peroxidase complex (ABC) method [7]. The primary antiserum was raised in rabbits against human PGP 9.5 (1:5,000, 13C4, Ultraclone Ltd., Isle of Wight, UK). It has been reported that this type of antiserum detects bovine PGP 9.5 [8]. The site of antigen-antibody reaction was visualized by a commercially available ABC kit (Vectastain Elite ABC kit, PK-6100, Vector Laboratories Inc., Burlingame, U.S.A.), and was developed in 3,3'-diaminobenzidin tetrahydrochloride solution containing $0.03 \% \mathrm{H}_{2} \mathrm{O}_{2}$.

The histological area in the tunica muscularis of each region was investigated under light microscopy. The density of the nervous element in the tunica muscularis was
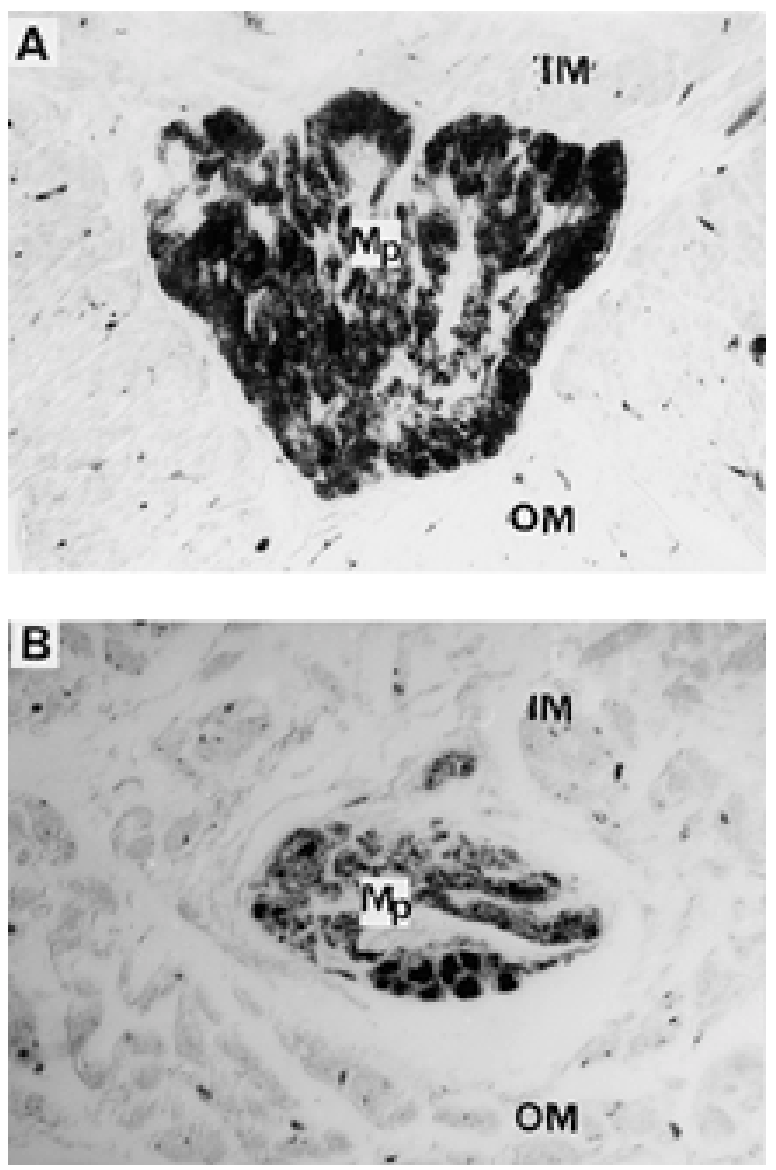

Fig. 2. Protein gene product 9.5-immunoreactive neuronal elements in the tunica muscularis of the corpus region of the greater curvature of the abomasum. A) Myenteric plexus (Mp) with nerve fibers and cell bodies is manifested between the inner (IM) and outer (OM) smooth muscle layer of a non-vagotomized calf ( 1 week old). $\times 60$. B) Neuronal elements in the myenteric plexus and muscle layers of a 5-week-old calf 4 weeks after vagotomy. $\times 60$.

ranked subjectively from 1 to 4 (1; very low density, 2 ; low density, 3; moderate density, 4; high density). A MannWhitney test was used for comparison of the control and vagotomized groups. $\mathrm{p}<0.05$ was considered statistically significant.

Radiograms of non vagotomized calves from 1 to 5 weeks old demonstrated that sucked milk containing contrast media entered through the reticular groove into the abomasum. On the other hand, in the vagotomized calf, the milk first entered the ruminoreticulum and then the abomasum. Atony with dilatation of the abomasum was detected 2 weeks after vagotomy. The radiopaque material was retained from the previous week in all vagotomized calves (Fig. 1A). Four weeks after vagotomy, the abomasum was still in a dilated condition in 2 calves, while in 2 others there was a marked impaction with ingesta in addition to the dilatation (Fig. 1B). 
A

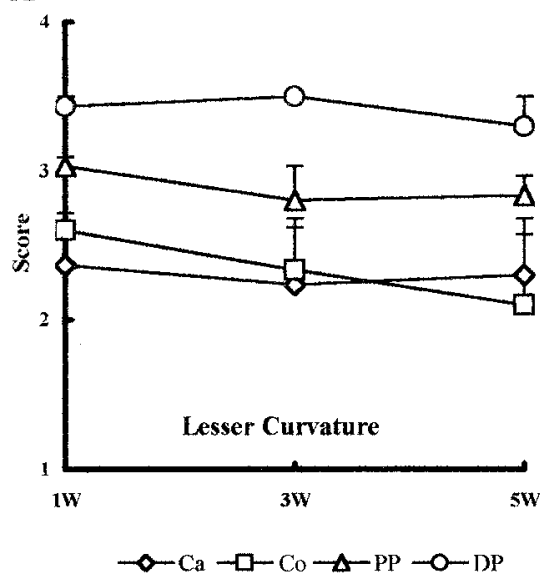

C

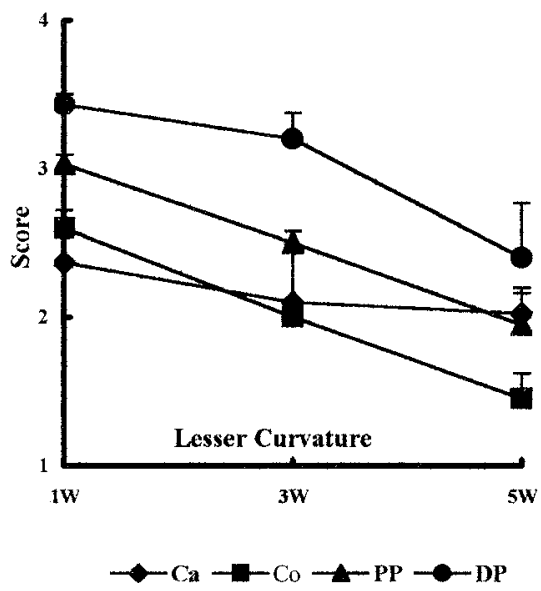

B

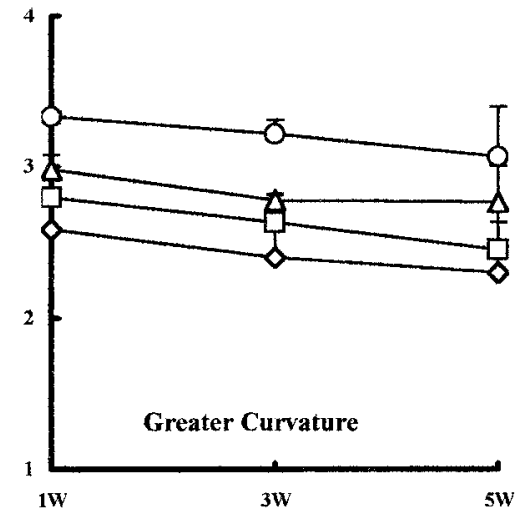

D

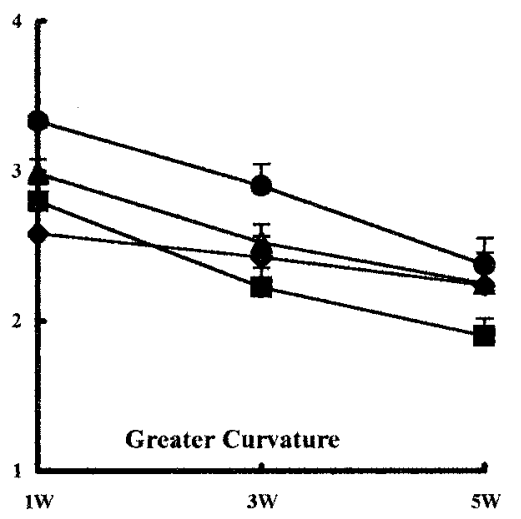

Fig. 3. Relative density of protein gene product 9.5-immunoreactive nervous elements in various regions of the lesser (A and C) and greater curvatures (B and D) of the abomasum from control (non-vagotomized: A, B) and vagotomized (C, D) calf. -Ca: Cardiac, -Co: Corpus, -PP: Proximal Pyloric, -DP: Distal Pyloric, W: week/s of age. Each symbol with vertical bar represents average density of innervation (grade \pm S.E.M).

In non-vagotomized calves, PGP 9.5 immunoreactivities were demonstrated in nerve cell bodies and nerve fibers of the tunica muscularis (Fig. 2A). Moreover, the relative densities observed with different ages (1, 3 and 5 weeks old) were not changed in both the lesser and greater curvatures (Fig. 3A and 3B).

On the other hand, in vagotomized calves, depending on the time interval after vagotomy, the density of PGP 9.5immunoreactive nerves tended to be decreased in comparison both with those of the previous week and with those of non vagotomized calves of the same age (Figs. 2B, 3C and $3 \mathrm{D})$. The density was most markedly decreased $(\mathrm{p}<0.01)$ in the corpus region of the greater curvature 2 weeks after vagotomy, and it was at its lowest 4 weeks after vagotomy in all regions examined. The nerve distributions particularly decreased significantly in the proximal $(p<0.05)$ and distal $(\mathrm{p}<0.05)$ areas of the pyloric region of the lesser curvature 4 weeks after vagotomy (Fig. 3C). Generally, PGP 9.5-immunoreactive nerves in the corpus, proximal and distal areas of the pyloric regions were more influenced than those in the cardiac region (Fig. 3D).

In this study the different ages of non vagotomized calves showed no significant differences in nerve density and distribution in the abomasal wall. This suggests that the maturity of calves during their nursing stage does not affect nerve density in the abomasal wall as it does in the case of the forestomach $[9,10]$. On the other hand, the vagotomized group demonstrated a decreasing tendency in the density of innervation with the length of the postoperative period. This may be caused by a decrease in extrinsic nerve fibers running through the muscle layers. This incidence of decrease coincided with that of calcitonin gene-related peptide- 
immunoreactive nerve fibers in the rat stomach after vagotomy [13].

The density of nervous elements in the non vagotomized calves was not so different among the regions of the abomasum other than the distal portion of the pyloric region in which it was slightly higher. On the other hand, the level of the influence of vagotomy differed among regions. The corpus region was influenced earlier and more severely than other regions. This finding may be related to the fact that vagotomy had a greater effect on the motor activity of the corpus than on that of the pyloric region of the abomasum $[1,21]$. Furthermore, it may also be associated with the more numerous vagal nerve endings in the lesser curvature than in the greater curvature [15]. It is suggested that the abomasum is subjected to a complex integrative relationship between the extrinsic and intrinsic nervous systems depending on the region. Abomasal disorders such as atony, dilatation and impaction after total vagotomy might be caused by disturbances of the integration systems due to the diminished control of the extrinsic nerves.

It is very interesting to note that after vagotomy, abomasal atony with dilatation and impaction occurred. From the clinical point of view, the present results should be considered as essential prerequisites for the occurrence of abomasal disorders such as abomasal displacements [3], impaction, and/or functional pyloric stenosis [2].

In conclusion, the present study indicates that a decreasing frequency of intramural nerves from the vagus nerve in the tunica muscularis could be one of the etiological factors in bovine abomasal disorders.

ACKNOWLEDGMENTS. We would like to thank Dr. R. J. $\mathrm{T}$. Ducusin for his generous help in improving the manuscript. This study was financially supported by a Grant-inAid for Scientific Research (C) (No. 10839001) from the Ministry of Education, Science, Sports and Culture of Japan.

\section{REFERENCES}

1. Bell, F. R., Holbrooke, S. E. and Titchen, D. A. 1977. J. Phys- iol. 272: 481-493.

2. Clark, C. H. 1953. Vet. Med. 48: 389-391.

3. Dirksen, G. 1961. Dtsch. Tieraerztl. Wochenschr. 68: 8-12.

4. Doran, J. F., Jackson, P., Kynoch, P. A. M. and Thompson, R. J. 1983. J. Neurochem. 40: 1542-1547.

5. Duncan, D. L. 1953. J. Physiol. 119: 157-169.

6. Grovum, W. L. 1986. pp. 18-40. In: Control of Digestion and Metabolism in Ruminants (Milligan, L. P., Grovum, W. L. and Dobson, A. eds.), Prientice-Hall, Englewood Cliffs, New Jersey.

7. Hsu, S., Raine, L. and Fanger, H. 1981. J. Histochem. Cytochem. 29: 577-580.

8. Jackson, P., Thomson, V. M. and Thompson, R. J. 1985. J. Neurochem. 45: 185-190.

9. Kitamura, N., Yamada, J. and Yamashita, T. 1986. J. Comp. Neurol. 248: 223-234.

10. Kitamura, N., Yamada, J. and Yamashita, T. 1987. J. Comp. Neurol. 256: 590-599.

11. Kosterlitz, H. W. 1968. pp. 2147-2171. In: Handbook of Physiology. Alimentary Canal, vol. 4. (Code, C. F. ed.), Am. Physiol. Soc., Bethesda, Washington D.C.

12. Krammer, H. J., Karahan, S. T., Rumpel, E., Klingen, M. and Kuhnel. 1993. Ann. Anat. 175: 321-325.

13. Lee, Y., Shiotani, Y., Hayashi, N., Kamada, T., Hilyard, C. J., Girgis, S. I., MacIntyre, I. and Tohyama, M. 1987. J. Neural. Transm. 68: 1-14.

14. Lowe, J., McDermott, H., Landon, M., Mayer, R. J. and Wilkinson, K. 1990. J. Pathol. 161: 153-160.

15. Morrison, A. R. and Habel, R. E. 1964. J. Comp. Neurol. 122: 297-309.

16. Neal, P. A. and Edwards, G. B. 1968. Vet. Rec. 82: 396-402.

17. Newhook, J. C. and Titchen, D. A. 1974. J. Physiol. 237: 415430.

18. Ruckebusch, Y. 1989. pp. 1225-1282. In: Handbook of Physiology. Motility and Circulation, Part 2 (Schultz, S. G. ed.), Am. Physiol. Soc., Bethesda, Washington D.C.

19. Teixeira, A. F., Wedel, T., Krammer, H.-J. and Kuhnel, W. 1998. Ann. Anat. 180: 393-400.

20. Thomson, R. J. and Day, I. N. M. 1988. pp. 209-228. In: Neuronal and Glial Protein (Structure, Functional and Clinical Application) (Marangos, P. J., Compbell, I. C. and Cohen, R. M. eds.), Academic Press, New York.

21. Wegrzyn, T. 1981. Acta Physiol. Pol. 32: 21-28.

22. Yamamoto, Y., Atoji, Y. and Suzuki, Y. 1995. Ann. Anat. 177: 405-412. 